\title{
"SLOW YOUR MOTIONS" INTERVENTIONS IN URBAN SPACES TOWARDS A LIVABLE NEIGHBORHOOD: CASE STUDY OF HAMM-NORD, GERMANY
}

\author{
JULIANE F. BENACHIO, XHELONA HAVERIKU, PATRICIA D. ZALUSKI, \\ HSIAO-HUI CHEN \& UDO DIETRICH \\ REAP (Resource Efficiency in Architecture and Planning) Research Group, \\ HafenCity University Hamburg, Germany
}

\begin{abstract}
This paper investigates the relationship between the concepts of a livable neighborhood and human perception. A literature review was carried out in order to collect and summarize the positive and negative effects urban structure, such as color, materials, and rhythm, might have on the users. A positive human perception can be achieved through an adapted design of neighborhoods in order to contribute to their livability. In addition, slowing down the movement and improving the pedestrian's perception through urban planning methods may lower the stress level, increase the use of public space, and even help the neighborhood economy. The proposal was developed entirely as an academic project part of the Resource Efficiency in Architecture and Planning master program (HafenCity University) towards a livable neighborhood project in Hamm-Nord, Hamburg, Germany. Interviews and surveys with the inhabitants were carried out to explore the effects of how urban design can affect the human perception and change their experience. Therefore, this study proposes that the speed of pedestrian movement can be slowed down by improving pedestrian connections, increasing interaction between different users and visual stimulation as urban interventions to increase the quality of life and affect their perception by applying ideas derivative from the livable neighborhood concept.

Keywords: livable neighborhood, human perception, human scale, urban interventions, walkability, facade diversity.
\end{abstract}

\section{INTRODUCTION}

Modern life conditions', such as the quality of the built environment, motivations, and daily life activities, can determine positively or negatively our capacity to observe and absorb the surrounding information. In order to acquire this information, the user of a public space needs to feel invited into a slower pace. In addition, the surroundings need to be interesting enough to create a pleasant experience, since humans need frequent stimuli [1]. However, most of the monotonous urban spaces that exist nowadays in the cities do not fulfil their role as a magnet for public interaction. Very often, they act as a repellent that discourages people to stay and to experience the urban landscape. The design strategies that include the consideration of slowing down the pedestrian's pace could potentially enhance the mental health via diverse stimuli and human scale focus.

In this paper, the concept of livable neighborhood is adapted to an academic project by improving pedestrian connections, interaction between different users and visual stimulation as urban interventions to increase the quality of life and affect their perception. One of the neighborhood quarters in Hamburg was chosen to be the focus of the study in order to identify its specific qualities and to develop specific solutions to the area. Although the results of the project will not be realized, it demonstrates how to slow down the speed of pedestrian movement through urban design.\# 


\section{LITERATURE REVIEW OF LIVABLE NEIGHBORHOODS}

What makes a neighborhood livable? How can livability be defined? Previous researchers have defined livability as "a statement of desires related to the contentment with life in a particular location" [2] and "a behavior-related function of the interaction between environmental characteristics and personal characteristics" [3]. Livability at its root is about living [4] and living for those people that seek enjoyment is something more than just fulfilling the human basic needs.

A Livable Neighborhood can be reached by building the urban structure with walkable, mixed-use areas, which encourage people to use the urban amenities. [5]. If many people are encouraged to walk in the pleasant and safe streets for everyday needs as well as for a recreational purpose, the community life may be improved, and the personal safety levels could increase [6]. Livable Neighborhoods consists of four general design "elements": community design, movement networks, lot layout and public parkland. These four elements provide design guidance to assist in creating more compact, self-sufficient, pedestrianfriendly neighborhoods, with destination hubs (i.e., neighborhood centers) and public transport links [7]. Livable Neighborhoods not only possess tangible but also intangible features, such as a sense of place, local identity, social networks and cultural capital [8], which are perfectly shown in the Plaza del Campo in Siena, Italy. Lastly, in order for a neighborhood to be defined as livable, it must be able to maintain and improve its viability (the capacity to attract continuous investment) and vitality (to remain alive) [9].

\subsection{The role of visual complexity and land use diversity on human perception}

Cities can be considered as ecosystems, human habitats, which are dynamical and complex systems characterized according to a variety of indicators, such as its population, density and wealth. Furthermore, cities can be physical structures based on human behavior. Two of the measurements for evaluating this physical process are entropy and diversity, which refer to the process that, during the years, humans formed their cities and urban shapes [10].

Entropy can be defined as the measurement of the change from order to disorder [11]. Diversity, as Jane Jacobs points out, should be created and offered if it is lacking in a neighborhood [12]. In a smaller urban form scale, such as a neighborhood or a street, the perceptions of human scale are assigned to the building heights and signage, while the perception of enclosure is connected to the gap between built elements as well as the presence of trees, functioning as shading or protection elements [13]. Balanced visual complexity relies on achieving equilibrium between order and disorder as well as creating some diversity [14]. In other words, the diversity is created by including visual complexity.

Visual complexity is directly related to the number of recognizable variations a human is offered while moving around the city. Moreover, people desire to acknowledge information at a comfortable proportion, since low levels of variety remove the senses while high levels overcome them [15], [16]. Therefore, the visual complexity varies according to the types of buildings, design details, street furniture, human activity, signage as well as street trees with a high variety of texture details [17].

The complexity can be reduced by top-down approaches, which is mainly controlled and predictable, creating big similarities between them, such as in a master plan. Urban spaces that have few urban design elements, too similar and predictable or very disordered can create an urban design with low complexity. On the contrary, buildings with different arrangements also increase visual complexity, as well as many diverse surfaces affect the flow of light [12]. Previous researchers have found that pedestrians with low-speed motion need a high level of visual complexity in order to maintain their attention, but drivers find the environment too 
disordered, due to the higher speed in which they receive the information [10]. However, the higher complexity can increase the motorists' attention, which could reduce accidents and create a safer space for pedestrians [17]. Furthermore, humans have higher interest and enjoyment in relation to urban environments with perceptual abundance [18].

Land use diversity is another important aspect in order to understand the complexity of an urban design. Mixed land use can produce positive synergies between the users and the urban space [12]. Therefore, the land use diversity can directly influence the human travel behavior inside the neighborhood [19].

Concisely, in order to slow down the speed of pedestrian movement, the design strategies should target the increase of visual complexity and land use diversity.

\subsection{The impact of the urban environment on mental health}

The effect of the surrounding environment of an urban neighborhood to human health is a concept that is becoming more consolidated. The quality of the urban environment surroundings affects humans [20] not only in regard to physical health but also in regard to mental health and emotional well-being. Fewer options for outdoor activities, from open spaces to commercial areas, result in people spending less time outdoors and reduce the satisfaction towards the neighborhood environment [21], [22].

Mental health can be divided into positive emotional states such as joy, tranquility, satisfaction, and sense of belonging, as well as negative ones, such as irritability, frustration, fear, boredom, and isolation [23]. Design characteristics of the urban environment can affect the mental health since they affect human perception, offering different levels of privacy and human interactions as well as their human responses. For example, if the user experiences fewer stimuli or interaction, this can create stress or frustration. If this result is continuous, it can escalate to long-term health issues [23].

The most influential design aspects related to mental health are street design, housing type, density, and community facilities. Negative experiences in an urban environment trigger an innate human behavior of protection/survival thus avoidance on repeating the situation [23]. Translating this into an urban scenario, the user avoids using the existing urban structure, reduces the time and frequency by only using necessary routes. In some extreme cases, residents may even move out in an attempt to reduce the experienced stress or discomfort. Therefore, the walkability of a neighborhood is a pertinent aspect of the urban vitality of the region.

A walkable area contains a mixture of land use. It is well connected within the region and to other parts of the city and it is accessible for pedestrians. Walkability is also associated with the presence of several good qualified gathering places, which provide social interaction and the prospect of good neighborly relations. It also culminates in a sense of belonging towards the home environment [21].

Surrounding's aesthetic is another relevant aspect, even though this is subject to personal preferences. Nonetheless, several studies have found the relationship between built environment aesthetics, the users' perception and its beneficial results to their health. When an urban area is positively aesthetically identified, this is transferred to positive mental states. This may result in the increased frequency and length of walks in people's daily routine [21], [24], [25].

Therefore, the urban design of an area is related to the functionality of its buildings, the planned open spaces and the connections between them. The users of this space do not only make use of the space, but they also experience it while developing emotional states as innate answers to what they encounter. This is one of the reasons why, when visiting some places, 
people feel comfortable and want to stay longer. Otherwise, the users can experience a sensation of restlessness and the urge to leave the area. This is the human mind translating the visual stimuli and social interactions into personal emotional states that make them respond in a physical way.

Concisely, the literature review provides guidelines to develop the urban design strategies targeting positive impacts on the mental health. The strategies include increasing the walkability of the neighborhood by improving the street design, connecting interesting spots, adopting mixed land use, creating planned open spaces and the connections between them.

\section{METHODOLOGY}

The urban analysis of the selected neighborhood quarter, Hamm-Nord in Hamburg, Germany, was carried out in order to collect information of the status quo of the area and to give a starting point to the assessment of the neighborhood. Firstly, several urban indicators [26] were calculated to measure the quantitative aspect of the quarter. As seen in Table 1, the land use is mainly residential and there is a lack of commercial use compared to the livable quarters of Hamburg. The reduction of the distances between intersections for the pedestrians as well as the increase of the cyclomatic number would benefit the pedestrian connectivity.

Table 1: Urban indicators of Hamm-Nord and average of 11 livable quarters in Hamburg [26].

\begin{tabular}{|l|c|c|c|c|c|c|c|c|}
\hline & $\begin{array}{c}\text { Cyclomatic number } \\
\text { (L-N }-\mathrm{N}) / \mathrm{A} \\
\mathrm{N}=\text { nodes; } \mathrm{L}=\text { links }\end{array}$ & $\begin{array}{c}\text { Average distance } \\
\text { between } \\
\text { intersections }\end{array}$ & $\begin{array}{c}\text { Pedestrian } \\
\text { sideways } \\
\text { width }\end{array}$ & $\begin{array}{c}\text { Building } \\
\text { Density }\end{array}$ & \multicolumn{2}{|c|}{ Land use of sub-center } \\
\hline $\begin{array}{l}\text { for cars } \\
{\left[1 / \mathrm{km}^{2}\right]}\end{array}$ & $\begin{array}{c}\text { for } \\
\text { pedestrians } \\
{\left[1 / \mathrm{km}^{2}\right]}\end{array}$ & $\begin{array}{c}\text { for } \\
\text { cars } \\
{[\mathrm{m}]}\end{array}$ & $\begin{array}{c}\text { for } \\
\text { pedestrians } \\
{[\mathrm{m}]}\end{array}$ & {$[\mathrm{m}]$} & $\begin{array}{c}\text { [Building } \\
\left./ \mathrm{km}^{2}\right]\end{array}$ & $\begin{array}{c}\text { Residential } \\
\text { multifamily } \\
{[\%]}\end{array}$ & $\begin{array}{c}\text { Commercial } \\
\text { (shops, } \\
\text { restaurants } \\
\text { etc. })[\%]\end{array}$ \\
\hline $\begin{array}{l}\text { Livable } \\
\text { quarter } \\
\text { average* }\end{array}$ & 40.90 & 59.90 & 176 & 103 & 4.10 & 794.73 & 46.71 & 15.72 \\
\hline $\begin{array}{l}\text { Hamm- } \\
\text { Nord }\end{array}$ & 55.00 & 67.00 & 133 & 133 & 3.00 & 863.00 & 72.40 & 5.40 \\
\hline *Average of 11 quarters that are generally accepted as the most livable ones in Hamburg & \\
\hline
\end{tabular}

Table 2: SWOT of the quarter status quo most relevant points.

\begin{tabular}{|c|c|c|c|}
\hline \multirow{4}{*}{ 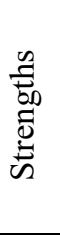 } & High green ratio (43\%) & \multirow{4}{*}{ 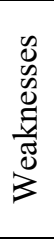 } & Lack of diversity (land use and aesthetic) \\
\hline & Proximity to city center $(5 \mathrm{~km})$ & & Car oriented quarter \\
\hline & $\begin{array}{l}\text { Presence of } 2 \text { poles (train station } \\
\text { and park) }\end{array}$ & & $\begin{array}{l}\text { Lack of quality open space and urban } \\
\text { furniture }\end{array}$ \\
\hline & Well maintained building facades & & Long continuous monotonous facades \\
\hline \multirow{3}{*}{ 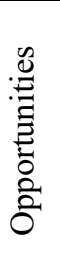 } & $\begin{array}{l}\text { Possibility of adding use to green } \\
\text { semi-public open spaces }\end{array}$ & \multirow{3}{*}{ 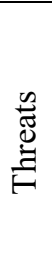 } & No investments in the commercial area \\
\hline & $\begin{array}{c}\text { Potential of developing mixed- } \\
\text { use in the intervention area }\end{array}$ & & $\begin{array}{l}\text { No collaboration from the owners and } \\
\text { inhabitants }\end{array}$ \\
\hline & $\begin{array}{l}\text { Potential to enhance the aesthetic } \\
\text { of post WW2 facades }\end{array}$ & & $\begin{array}{l}\text { Low acceptance of the proposal } \\
\text { by the users }\end{array}$ \\
\hline
\end{tabular}


Secondly, maps analyzing the gradient between public to private zones, land use, street hierarchy, and connectivity to public transports were employed to collect the mentioned information. Thirdly, a SWOT analysis of the quarter status quo is developed to identify its strengths and weaknesses (see Table 2).

Fourthly, the authors also visited the site area to collect first-hand and personal impressions of how people, including the researchers, experienced the region. An on-site interview with inhabitants and bystanders was also carried out to collect basic information (i.e. age, gender, proximity to work, means of transport in the area and others). In order to broadly collect some ideas of how people perceive the area, inhabitants were asked about some specific details about architecture and urban-related questions (i.e. satisfaction with colors and materials of facades and sidewalks, the use of the open spaces and the satisfaction with the land use of the area). The authors also made several visits to the location in order to experience the area in person and to make photo documentation of the buildings, streets and the relation between them. Study plans and sections were also developed with the aim to understand the relationship between the constructed spaces.

Fifthly, in order to test the study's hypothesis about the negative effect of the monotonous facade on human perception a multiple-choice questionnaire based on the SWOT and status quo analysis of Hamm-Nord quarter was used on site and on an online platform. The surveys were carried out to understand the expectations, necessities, and engagement of the quarter's inhabitants. Questions with general information of the interviewees and focused questions in relation to use and frequency of opens spaces, used means of transport, facades satisfaction and preferences of facade materials as well as the reason for choosing to live in this neighborhood. The online survey was distributed through the group's e-mail list of HafenCity University Hamburg (HCU), University of the Built Environment and Metropolitan Development. This may be beneficial, since it is related to the subject at hand, therefore with the possibility of higher awareness regarding the subject. The questionnaire was also sent to the community online platform [27]. This variety of the subject groups and the multiple means of the survey might increase the representation of the findings in the study.

Of a total of 42 interviewees, with regards to the user's impression of the continuous brick facades, $55 \%$ thought it was acceptable, however, $20 \%$ were against. With the analysis of the questionnaire, it was found a relationship between time spent outdoors and the impressions of the users of the building's facades. Since they do not spend much time on open spaces in the neighborhood, it can be assumed that they may have a decreased perception of the facades. Therefore, it seems that those who rarely use open spaces appreciate the facades and find them acceptable.

The results of the survey also show that, regarding the use of the open spaces frequency in Hamm-Nord, the inhabitants mainly enjoy it once a week or almost never, which results in empty plazas and open spaces. When questioned about the satisfaction of living in HammNord, $50 \%$ of them were positive about the proximity to the city center. Moreover, the residents mainly connect with the city by metro or other means of public transportation. Concerning the services that the neighborhood does not offer, the respondents pointed the lack of entertainment, such as bars. In addition, the collected survey answers were compared with the district status quo analysis resulting in some assumptions that serve as the basis to develop solutions that could answer the questions raised by the current study.

In the sixth step, an area was identified between a train station and a park as a possible intervention site due to the potential to attract users as well as the availability of semipublic spaces to increase the connection from one pole to another. Specificities of the area should also be taken into consideration, such as any preservation or heritage status. 
Finally, the concept of "Slow Your Motions" was subsequently developed taking into consideration the issues and aiming for a feasible urban project. The project plans and image visualizations of the designed interventions were created. The final objective would be to show the created result to the possible users of the area (inhabitants, investors, and municipality) and collect their feedback. Even though this is an academic project, it still displays the possibilities of enhancing an existing urban area into a livable neighborhood by focusing on the human scale and incorporating the user's participation.

\section{CASE STUDY: HAMM-NORD}

Hamm-Nord is situated $5 \mathrm{~km}$ away from the city center and has three sub-centers. The quarter is connected to other areas of Hamburg by three underground stations.

In order to have a deeper understanding of the quarter, the analysis focuses on an area with a dimension of 1 by $1 \mathrm{~km}$. The neighborhood is mainly residential with $21 \%$ of builtarea. Regarding open spaces usage, $43 \%$ is occupied by green areas and $7.5 \%$ by sidewalks and plazas. Semi-public spaces compose more than half of the area. Concerning the quality of public spaces, the neighborhood lacks plazas and public furniture. Additionally, the case study quarter can be considered as car-oriented, due to the high traffic volume and many parking places that surround almost every street (see Fig. 1).

Most of the buildings consist of 4 to 5 stories and are arranged in the perimeter of the block, one next to another. Together with the brick facades, they make the whole block extension appear as a single building with a continuous facade. The building's arrangement creates semi-public inner courtyards, which are mainly covered by grass, with no attraction or use. Moreover, this typology does not permit visual permeability to the inner block. In order to obtain the aim of the case study, the chosen area of intervention has a smaller dimension, around 300 by $600 \mathrm{~m}$, with approximately four blocks between Sievekingdamm and Carl-Peterson Street (see Fig. 1).

\subsection{The concept of "Slow Your Motions"}

The SWOT analysis of Hamm-Nord quarter, based on its status quo, shows the strengths of high green ratio (43\%), easy accessibility to public transportation $(73 \%$ of buildings in a $300 \mathrm{~m}$ radius are connected to public transit stops) and proximity to the city center (approx. $5 \mathrm{~km})$. Therefore, the current study proposes to enhance the semi-public open spaces into interactive public spaces. Moreover, weekly market, parks, sport activities and community engagement through the web blog "Hamm wir alles" [27] are also positive aspects of the quarter. However, the study area also presents many weaknesses, such as the lack of urban furniture and a car-oriented neighborhood. Furthermore, regarding the building typology, the continuous brick facades express a monotonous view with no focal point, which reduces the stimuli at pedestrians' eye level. The attractiveness of a space is determined by functional diversity as well as volumetric distinction. In Hamm-Nord, through observation and surveys, it was assumed that the urban arrangement of volumetric diversity in regard to buildings height is not a major issue. An example of how to intervene and change a continuous facade is by indentation, protuberance or changing its use as seen in Fig. 2. In this quarter, the focus was to concentrate on the pedestrians' eye level perception by aiming on the ground floor, introducing commercial uses to a current residential area in order to achieve functional diversity. Moreover, to create volumetric distinction it is more effective to intervene in the area by adding protuberances to the front facades. 


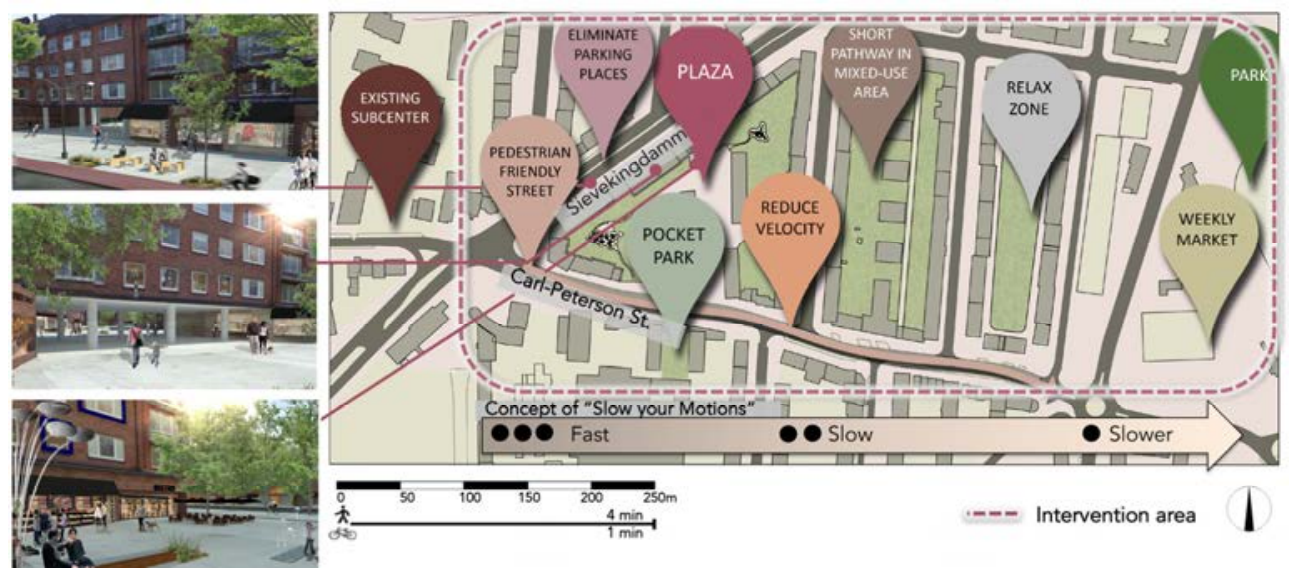

Figure 1: (Left) Visualization of new commercial use, proposed passage and plaza. (Right) Proposed urban intervention plan.
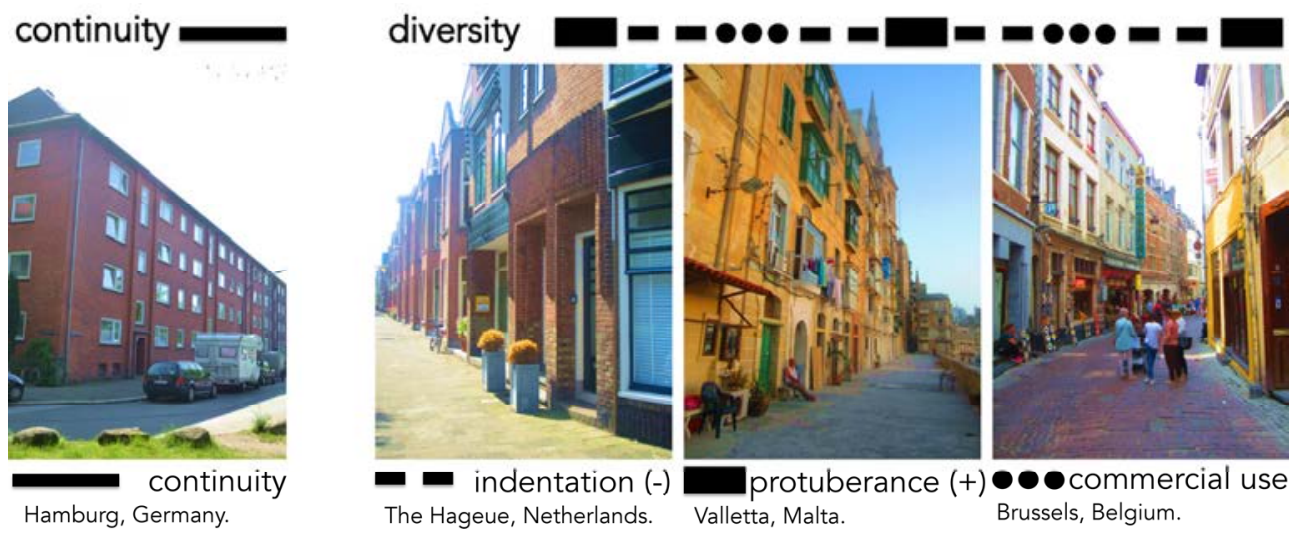

Figure 2: Comparison between continuous and diverse facades. (Source: Pictures taken by authors.)

Based on all the analysis, the project had the goal to implement livable neighborhood concepts, which aims to design an accessible, inviting, interactive, sociable, vital, multifunctional, safe, clean, walkable, attractive for staying, visual and "green" quarter. In order to reach these objectives, the concept of "Slow Your Motions" was developed in which the users will perceive the urban landscape with the new buildings' facades diversity. Moreover, visual permeability will create a sense of 'relieve' from the continuous building line from a pedestrian perspective. Furthermore, introducing different uses of space such as more commercial services in the area of intervention, within walkable distances, will generate visual diversity and attraction of uses. 


\subsection{Derivation of detailed interventions}

The proposed concept of "Slow Your Motions" can be further divided into two main interventions that target 1) increasing land use diversity and connectivity of interesting places and 2) increasing visual complexity. The land use diversity can be increased by focusing on the horizontal perception of the space by the users toward sustainable urbanism. The visual complexity can be increased by focusing on the vertical perception of the facade materials.

\subsubsection{Increasing land use diversity and connectivity of interesting places}

The main objectives of this project are the creation of a livable sub-center, plazas and pedestrian pathways, and the connections between existing main magnet areas of the neighborhood. The detailed description of the design strategies to increase walkability and to slow down the pedestrian motion are explained in this section.

Firstly, there is the potential of further developing the current sub-center and other points of interest, such as the weekly market and parks. Secondly, there is also the potential to develop a mixed-use area that relies on the shops' intensity and the ease of accessibility to public transport serving this area. Therefore, Carl-Petersen street is fragmented in different areas in order to reduce the distances of built and non-built spaces, displaying an irregular pattern and creating a surprise effect during the pedestrian route.

The first zone, the plaza, is located near to the existing public transport stations. In order to increase the accessibility to this new area and attract more pedestrians from the Sievekingdamm street, a passage on the ground floor of one of the residential buildings is created (see Fig. 1). The new connection between the two main streets generates a short path turning the plaza into a more inviting and livable space.

This area offers a high amount of possible interactions, in which diverse activities, such as playgrounds, and recreational activities, are accessible. The area does not have any water body or water features. Therefore, the proposal includes the small water basins to change the microclimate inside the plaza, which may as well be a place of entertainment for children.

The second block of the intervention area already has a pedestrian path, which will be continued until the other side of the block in order to create more pedestrian connections. The third block of the case study has the aim to create a relaxing zone in the existing inner courtyard by introducing a more casual design with an irregular pattern of comfortable seating area for different activities, such as reading and landscape contemplation.

By introducing multiple uses to the area during day and night, this intervention project will attract people to the plaza and pedestrian street, leading to a more vibrant district. The proximity to the city center is identified as a positive aspect since it can be a catalyst for investments in retail in this new development. A mix of activities promotes the diverse image and the flexible character of the area.

Thirdly, the connection proposed between these important spots of the neighborhood will transform Carl-Petersen into a pedestrian-oriented street, which can improve the walkability of the quarter while increasing the quality of sidewalks. Moreover, it can also reduce its car dominant status by raising the street to the same level as the sidewalks and slow down the traffic by reducing the speed limit to $25 \mathrm{~km} / \mathrm{h}$. The street pavement material also needs to be changed. Moreover, the sidewalk of Sievekingdamm, only in the intervention area, has its parking places removed and redesigned with urban furniture and allocating more space for pedestrians (see Fig. 1).

This street is going to be the meeting place and social center of the neighborhood, connecting not only the inhabitants but also visitors from the surrounding neighborhoods. Finally, the place-making concept will be used in the creation of the urban design as a 
participatory tool to involve and connect the residents in order to develop the sense of belonging toward the neighborhood.

4.2.2 Increasing visual complexity by improving facades of the buildings

In cities, diversity draws liveliness while monotony rejects concepts of livability [12]. This proposal, therefore, focuses on creating diversity in materials and shapes of the facades in three points: building's entrance, commercial areas on the ground floor and windows on the upper floors.

The intervention focuses on the vertical perception of the space, specifically in the facades. It targets at the monotonous linear fenestration with no focal point, following a continuing building line with the same material that is the typical Hamburg's red brick as seen in Fig. 3. A livable neighborhood must be perceived to be suitable for human scale. According to Gehl [1], pedestrians have a normal speed of $5 \mathrm{~km} / \mathrm{h}$. Therefore, the stimulus is needed at eye level every five seconds $(10-15 \mathrm{~m})$. In a walkable neighborhood, not only the physical distances are crucial, but also the perceived distances.

The aim of the intervention proposal is the building distinction in order to give different information to the human's brain and intervening at the human perception of space. It also intends to diversify the building materials without losing the bricks characteristic while enhancing its aesthetical potential. The changes on the facades will provide aesthetic experiences in three different stages: sensory perception through feeling, cognition through knowing, and finally the meaning, which is the conclusion of the experience. By diversifying materials of the facades, this will benefit the quality of life (livability, attractiveness, pleasantness) in the neighborhood. Following Gehl's [1] concept of human scale and human perception of surroundings and distances, this study proposes that the change of the whole facade is not necessary. It is enough to have interventions mostly on the ground floor, where the pedestrian perception is focused.

Since the whole quarter was constructed at once after the World War 2 (WW2), all buildings have the same brick continuous facades. For this reason, the choice of facades for improvement were based on the ones that are most seen by pedestrians. As a first part of the facade intervention, a new window pattern is proposed in order to break the monotonous linear fenestration. Therefore, additional elements on the windows are proposed, which will add volume and rhythm with two different shapes of elements. The window elements will be distributed in three different ways to provide a dynamic facade. The proposed types are the single-window element, the horizontal two-windows element, and the vertical two-windows
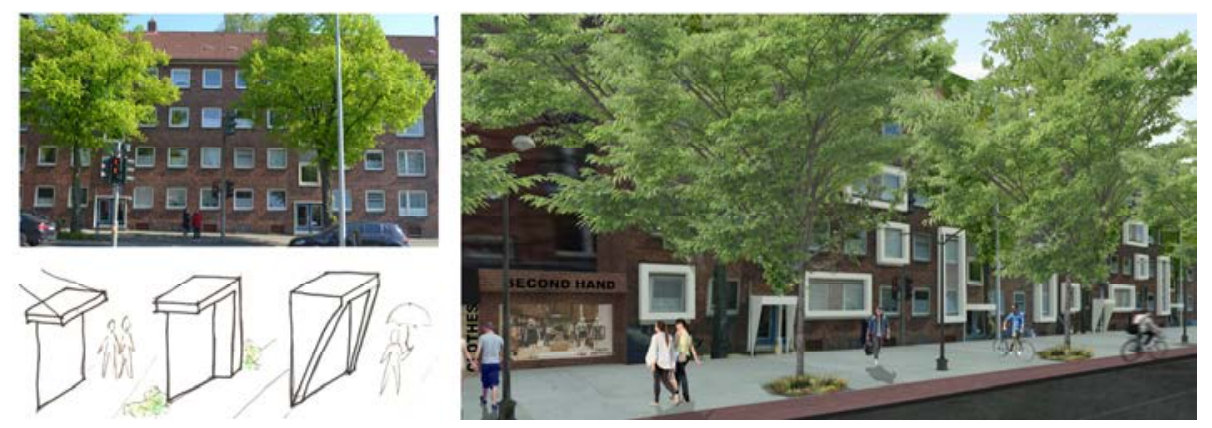

Figure 3: (Top left) Facade before intervention. (Bottom left) Types of proposed building entrances. (Right) Visualization of window, entrance and commercial ground floor interventions. (Source: Pictures taken by authors.) 
element. All interventions could be realized by only adding a few elements to the existing facades at a low cost and reduced disturbance. This intervention was merely aesthetical, nevertheless, with high visual impact.

The entrance of the buildings in this proposal can be categorized into three types of urban situations. Their main function is the rain protection. However, it is also marked as the entrances for residents to easily distinguish the main access of the buildings. The first type consists of a hanged horizontal shade, which is appropriate for the intense traffic sidewalk. The second type is an L-shape cover, which is suitable for the low-traffic sidewalks with a garden buffer. Finally, the third type has a U-shape cover with slopes in both vertical sides of the entrance that is also used for the low traffic sidewalks. It is also an option to create visual diversity in the area (see Fig. 3).

As it is shown in Fig. 4, the study distinguishes four types of facade interventions. The first one consists of alterations on the facade of commercial use in buildings with one story. The second alteration is on the commercial use facades, in this case, located on the ground level of multi-story mixed-use buildings (see Fig. 1). The third type is the addition of window's elements on the facade of the selected buildings (see Fig. 3). Finally, the fourth intervention alters the ground floor of residential buildings into commercial use. In the main intervention streets and new pedestrian paths, the gap between interventions in the use or on the facades did not reach more than $100 \mathrm{~m}$ with the aim to create a dynamic rhythm interfering positively in the pedestrians' perception of the area.

\section{CONCLUSIONS}

Based on the literature review of the four general design elements of Livable Neighborhoods, a few more strategies were developed to target the improvement of walkability as well as to slow down the speed of pedestrian movement. The first one was to improve the public parkland and community design by increasing the land use diversity, developing sub-center, creating points of interest, increasing the functionality of the buildings, the second one was to facilitate movement networks by enhancing pedestrian connections, street design and the last one was to increase visual complexity by improving facades of the building.

By exploring further in some of the concepts and analyzing the weaknesses and the strengths of the selected site, the current study proposes interventions with minimal cost and disturbance to the users and transforms the area into a more walkable and pleasantly

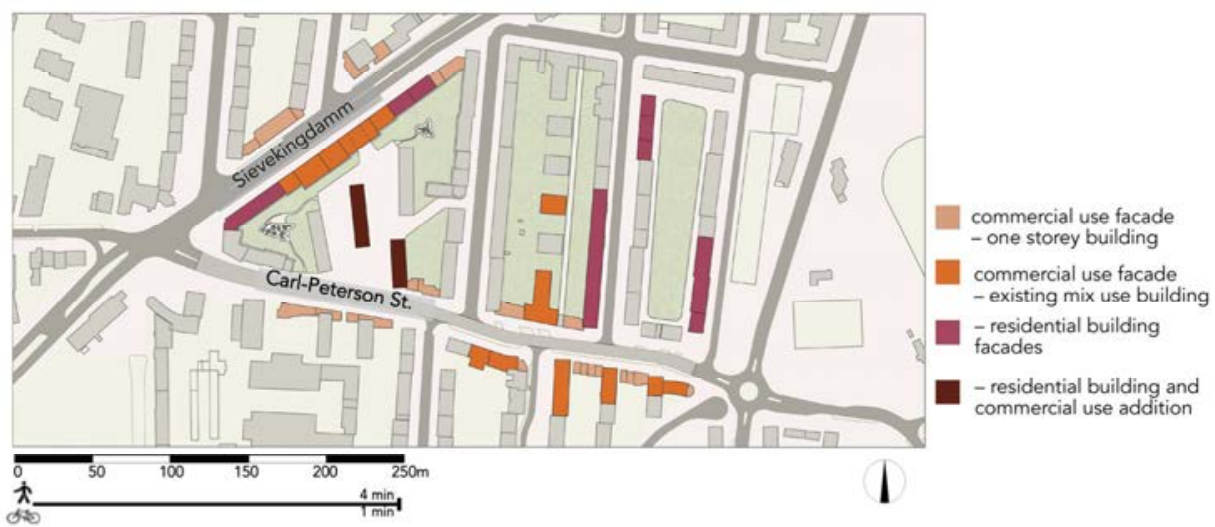

Figure 4: Different types of facade interventions plan. 
perceived neighborhood. Through urban design interventions, such as building the urban structure with pedestrian friendly and mixed-use areas conjointly with the human scale and perception focus, it is possible to encourage people to use the urban amenities of this livable neighborhood. This enhances the quality of their experience, which can have positive effects on the neighborhood's economy (higher number of pedestrians enhance the possibility of consuming on the shops of the area). It also enhances the sense of belonging with the creation of neighborhood identity. The quarter lacked one, due to the quick post WW2 constructions with the repetitive brick buildings facades. The inhabitant's participation in the new identity was considered in the survey process and applied to the case study. Moreover, improves the social connection and, therefore, has a positive impact on the mental health and the wellbeing of the residents.

\section{REFERENCES}

[1] Gehl, J., Cities for People, Island Press: Washington DC, USA, 2010.

[2] De Chazal, J., A systems approach to livability and sustainability: Defining terms and mapping relationships to link desires with ecological opportunities and constraints. Systems Research and Behavioral Science, 27(5), pp. 585-597, 2010.

[3] Pacione, M., Urban liveability: A review. Urban Geography, 11(1), pp. 1-30, 1990.

[4] Zarin, B. \& Tarantash, M., Neighborhood, Sustainability, Livability. Singapore: National University of Singapore. The 5th International Conference of the International Forum on Urbanism (IFoU), 2011, Online. http://globalvisions2011. ifou.org/Index/Group\%201/FOUA00088-00249P2.pdf. Accessed on: 18 Mar. 2018.

[5] Western Australian Planning Commision. Livable Neighborhoods - Street Layout, Design and Traffic Management Guidelines. Perth, Australia, Online. http://ipweaq. intersearch.com.au/ipweaqjspui/bitstream/1/3020/1/LNTMG.pdf. Accessed on: 18 Mar. 2018.

[6] Jones, E., Livable Neighborhoods. World Transport Policy and Practice, Perth, Australia, 7(2), pp. 28-43, Online. http://www.eco-logica.co.uk/pdf/ wtpp07.2.pdf\#page=38. Accessed on: 18 Mar. 2018.

[7] Hooper, P., Knuiman, M., Foster, S. \& Giles-Corti, B., The building blocks of a "Livable Neighbourhood": Identifying the key performance indicators for walking of an operational planning policy in Perth, Western Australia. Health \& Place, 36, pp. 173-183, Online. https://minerva-access.unimelb.edu.au/bitstream/handle/11343/ 115350/Hooper_2015.pdf? sequence=1. Accessed on: 18 Mar. 2018.

[8] Throsby, D., Cultural heritage as financial asset in strategies for urban development and poverty alleviation. Paper for International Conference for Integrating Urban Knowledge \& Practice, Gothenburg, Sweden, 2005.

[9] Balsas, C.J.L., Measuring the livability of an urban centre: An exploratory study of key performance indicators. Planning, Practice and Research, 19(1), pp. 101-110, 2004.

[10] Boeing, G., Measuring the Complexity of Urban Form and Design. Department of City and Regional Planning, University of California, Online. https://arxiv.org/ pdf/1705.01986.pdf. Accessed on: 18 Mar. 2018.

[11] Vocabulary, Entropy. https://www.vocabulary.com/dictionary/entropy. Accessed on: 17 Mar. 2018

[12] Jacobs, J., The Death and Life of Great American Cities, New York, 1961.

[13] Clifton, K., Ewing, R., Knaap, G. \& Song, Y., Quantitative analysis of urban form: a multidisciplinary review. Journal of Urbanism: International Research on Placemaking and Urban Sustainability, pp. 17-45, 2008. 
[14] Elsheshtawy, Y., Urban complexity: toward the measurement of the physical complexity of street-scapes. Journal of Architectural and Planning Research, pp. 301316, 1997.

[15] Ewing, R. \& Clemente, O., Measuring urban design: metrics for livable places, Washington, 2013.

[16] Ewing, R. \& Handy, S., Measuring the unmeasurable: urban design qualities related to walkability. Journal of Urban Design, 14(1), pp. 65-84, 2009.

[17] Dumbaugh, E. \& Li, W., Designing for the safety of pedestrians, cyclists, and motorists in urban environments. Journal of the American Planning Association, pp. 69-88, 2011.

[18] Marshall, S., Planning, design and the complexity of cities. Complexity Theories of Cities Have Come of Age, pp. 191-205, 2012.

[19] Cervero, R. \& Kockelman, K., Travel Demand and the 3 Ds: Density, Diversity, and Design, pp. 199-219, 1997.

[20] Ellin, A., Your city yourself. Imperfect Health - The Medicalization of Architecture, Canadian Centre for Architecture, Lars Müller Publishers: Zurich, pp. 251-265, 2012.

[21] Glasgow Centre for Population Health (GCPH), Health and the Physical Characteristics of Urban Neighbourhoods: A Critical Literature Review, Online. www.gcph.co.uk/assets/0000/0447/Health_and_the_Physical_Characteristics_of_Urb an_Neighbourhoods.pdf. Accessed on: $18 \overline{\text { Mar. }} 201 \overline{8}$.

[22] Francis, J., Giles-Corti, B., Wood, L. \& Knuiman, M., Creating sense of community: The role of public space. Journal of Environmental Psychology, 32, pp. 401-409, 2012.

[23] Hess, R.E. \& Wandersman, A., Beyond the Individual: Environmental Approaches and Prevention, The Haworth Press: New York and London, pp. 79-100, 1985.

[24] Humpel, N., Owen, N., Iverson, D., Leslie, E. \& Bauman, A., Perceived environment attributes, residential location and walking for particular purposes. American Journal of Preventative Medicine, 26(2), pp. 119-125, 2004.

[25] Humpel, N., Marshall, A.L., Leslie, E., Bauman, A. \& Owen, N., Changes in neighbourhood walking are related to changes in perceptions of environmental attributes. Annals of Behavioural Medicine, 27, pp. 60-67, 2004.

[26] Chen, H. \& Dietrich, U., Measuring liveability at neighbourhood scale - development of indicators and methods for the comparison between quarters and best practice within the chosen city. Central Europe Towards Sustainable Building CESB Conference SBE Series: Prague, to be published 2019.

[27] Afridi, S., Benachio, J., Burduh, A., Haveriku, Xh. \& Zaluski, P., Is Hamm-Nord a liveable neighborhood? Online. https://www.hamm-wir-alles.de/is-hamm-nord-aliveable-neighborhood. Accessed on: 26 Mar. 2018. 